\title{
住宅小区建筑规划设计的主要构思与设计方法
}

周聪

梧州市城乡建设规划设计院

DOI:10.32629/btr.v2i7.2374

[摘 要] 随着社会经济发展, 人们对居住环境的要求也在不断提高, 给住宅小区的建筑规划设计带来了越来越大的挑战,住宅 小区的建筑规划设计除了要满足居民舒适度要求的同时还要满足居民的精神需求,与此同时,还应符合现代化环保节能理念, 从而实现住宅小区的建筑规划设计水平的全面提升, 因此, 有必要对住宅小区的建筑规划设计的主要构思与方法加以研究分析, 有效推动住宅小区的建筑规划设计发展。

[关键词] 住宅小区; 建筑规划设计；主要构思

\section{1 住宅小区规划建筑的设计原则}

1. 1 以人为本

在对住宅小区进行详细规划时必须要考虑以人为本的 原则, 只有强调以人为本, 符合现代人的生活规律, 才能够让 现在的住宅小区更加的殹意舒适, 从而提高人们的工作效率 和生活效率。通过为业主打造一种充满绿意、自然生态、和 谐健康的居住环境, 配备高质量的公共服务设施能够进一步 方便人们的使用。

\section{2 绿色生态}

通过在绿地设计各种景观轴线来促进社区的各个空间 形成立体化的交叉景观特点, 能够深入贯彻可持续发展的目 标, 并且将绿色建筑空间作为整个环境的管理目标, 既能满 足住宅的舒适要求又能够为住宅的发展提供充足的合理空 间布置, 满足现代化的生活家园。

\section{3 经济节约}

要合理分配生产、生活、绿化、景观、交通等各种用地 之间的比例关系, 提高土地使用率。节能的技术原理是通过 蓄热等措施减少能源消耗, 提高能源的使用效率, 并充分利 用可再生的自然资源, 包括太阳能、风能、水利能、海洋能、 生物能等, 减少对于不可再生资源的使用。在建筑设计中结 合不同的气候特点, 依据太阳的运行规律和风的形成规律, 利用太阳光和通风等节能措施达到减少能耗的目的。

\section{4 操作性强}

在针对住宅小区规划的过程中必须要针对实际的地形 条件进行分析, 只有针对地形条件进行充分的整合与利用, 才能够满足人们的日常生活需求, 另外在户型配备方面, 必 须要考虑多样化的需求, 这样才能够为不同的群体都能够提 供适合他们的生活户型。

\section{5 高科技原则}

随着现代科学技术的快速发展, 各种新观念、新技术、 新材料在生活中广泛应用, 为此必须要通过高科技的方式来 提高住宅建筑的整体质量, 保证整个住宅空间更加的智能 化、高效化。

2 住宅小区建筑规划设计的主要构思

\section{1 自然的理念}

在对住宅小区进行规划设计时, 应重视建筑与自然的和 谐统一。首先, 应最大程度地利用现有条件, 适当地对小区周 边环境进行整合与改造, 避免对其周边生态环境产生过大的 影响; 其次, 对于小区周边环境中的一些不利因素, 硬座要做 针对性的处理, 使其向着优势、特色转变。总之, 在对小区进 行规划时, 必须重视起人与自然的和谐统一。

2.2 实现住宅环境资源均享

住宅小区规划设计过程中一个必要的设计环节就是实 现住宅环境资源均享, 即在设计规过程中保证住宅小区环境 的均好性。第一, 在具体设计过程中要保证每栋住宅建筑所 处位置都能够一样好, 同时有着各自的优势, 从而让客户在 进行住宅选购时都能够选择符合自己喜好的住宅。例如位于 前排的房子可以望江。位于侧面的房子正对园景、位于后排 的房子可以望山等。第二, 对于同一楼层来说, 都能够保证足 够的通风、采光, 并且对外景观及时不能保证相同, 也要各具 特色, 整体上都能够保证一样好。第三, 对于同一套房子来说, 每一个空间的景致均要相若, 严禁出现诸如黑则等问题。

\section{3 重视交通道路的建设}

“要想富先修路”。在中国发展中, 历史已经证明了这句 话的精髓所在。如今的社会, 出门便是条条宽阔的马路, 为人 们的出行带来了极大的方便。也正是这些道路, 才使得天南 海北的人能够聚在一起进行文化以及知识等的交流, 与此同 时, 交通运输需要平整的道路。因此, 住宅小区的建筑规划设 计过程中, 交通道路占有重要的地位, 起到提纲彗领的作用, 它不仅是方便小区内人们交通往来的重要通道, 更体现设计 者对小区整体交通系统的把握。

2.4 关于社区的理念

住宅小区的规划不同于商业建筑的设计, 其作为一个大 范围的居住环境, 应从整体对其进行考虑, 即必须要坚持社 区的理念。在对住宅小区的空间布局进行规划时, 应做到围 合内向, 促使建筑呈现出空间上的聚合性; 其次, 应根据不同 的区域特点, 为小区增加相应的配置, 增强社区归属感。

\section{3. 住宅小区的建筑规划设计的设计方法}


3.1合理进行选址规划

对于小区的选址规划在某种程度上决定着这一小区人 文特色与自然环境, 因此做好小区地址科学合理的规划是一 项成功的住宅小区设计规划的前提条件。具体来说, 选择小 区地址应确定小区地质条件是否优良, 同时结合小区周边交 通环境、人文环境、自然环境等进行合理的选择, 尽量保证 上述因素都能够满足且达到居住标准, 避免选择风口位置及 光照不充足的位置, 结合分析当地夏季主导风向加以合理分 析, 将建筑朝向设计为逆风朝向, 能够保证小区自然风充足, 并结合实际太阳角度及方位角变化, 确保整个小区建筑良好 的通风及光照充足。与此同时, 还要对小区住宅朝向、彼此 之间间距进行合理地规划设计, 确保与周边水文条件、地质 条件相协调。

\section{2 组成形式的应用}

从整体上来看中国当代的住宅小区的建筑规划设计, 体 现的是一种宏伟的气势, 而观察其细节, 则会发现, 即便是最 棘手之处, 也综合运用了大量的基础元素, 所谓的细节之处 见成败, 中国的住宅小区的建筑规划设计不放过任何部分, 甚至可以接受最严酷的工艺考察。住宅小区的整体是由每一 个小部分来组成的, 局部的形式效果以及其组成成分的多 少、组成元素类型直接关系到设计成果呈现出来的视觉好 坏。由此可以看出, 中国当代住宅小区的建筑规划设计手法 与品质冊庸置疑, 这便让人们开始思考它莫大信心的所在之 处, 即是源于中国悠久的建筑设计的独具匠心的地方。例如, 我在建筑住宅小区的时候, 尤其注重其构成, 为了突出住宅 小区具有立体的层次感, 特意加大了水泥的型号, 这样才能 使得建筑物在合理的组成过程中被固定住。

3. 3道路交通与坚向设计

小区内部和周围交通的设置上充分从人文角度考虑, 分 别设置了车道和人行道, 做到了人车分流管制系统。车行路 主要采取的是S型包围式道路, 根据住宅建筑的走向, 延伸到 每个独栋的门口或者地下车库的入口, 最大限度地节省了行 车距离, 也不会和人行道路产生重叠, 导致双方通行受阻; 步 行道路从小区正门口延伸到每一个板块内部, 主要涵盖住宅 区、公共服务区、景观区、物业区等等, 使各个组块之间有 效地连接在一起, 提高整体的统一性, 各个板块之间人行通 道互联互通, 步行距离控制在最短的范围内, 实现真正的人 车分流。另外在交通系统的建立上, 合理安排了地上的行车 路线、步行路线和地下车库之间的通行路线, 设置的半地下
停车场能够有效协调住户和停车位占有比例, 并且会减少地 下车辆对地上行人活动的影响, 提高地上行人的安全保障, 使得停车活动也更为高效。半地下停车场促进了地上人行道 路更加简洁通畅, 充分考虑到了上下班拥堵现象, 人车之间 的界限十分明了。另外, 半地下的设计还可以改善地下环境 的压抑性和封闭性, 采光和空气的流通会得到改善, 照明设 施成本还会有效地降低, 还可以减少车库人员巡逻的精力, 减 少业主公摊的地下室照明通风费, 提高业主的居住满意度。

\section{4 景观设计的应用}

中国住宅小区的建筑规划设计涉及了很多独到的手法, 例如, 近景与远景的搭配等。在景观设计这一模块, 它很重视 动态景物与静态景物的结合, 以给人一种自然而然的感觉, 既不显得刻意, 也不表现的很唐突, 而是让参观者觉得一切 都很舒适。在景观设计这方面, 中国当代住宅小区建筑工程 设计已经采用了因地制宜的建筑风格。我一直以来对住宅小 区的建筑设计十分热爱, 并亲自设计了一些小区住宅, 其中 就借鉴了中国古典建筑的手法, 即是从长廊的一个落脚点可 以遥望到远处的湖水和风中摇曳的枝条, 站在整体住宅的中 心位置, 则可以看见美丽的周围框架结构等。整个景观紧密 相连, 呈现出和谐的状态。比如, 在设计物周围景观的时候, 布置了大量的树加以祄托, 这样使得整个住宅小区看起来不 仅气势恢宏, 更能使居住者在小区中感受到移步异景的景观 享受, 在感官上有的只是无限美感。

\section{4 结语}

随着人们生活水平和生活品质的提高, 人们对住宅需求 的期望值也不断提高, 此时的住宅建筑无论是在设计, 还是 在环境规划上都有了更高的挑战。住宅建筑在设计时，一定 要以人为本, 凸显出自己的个性和特色, 并且还需要将人工 建筑和自然建筑相结合, 做到建筑、自然环境、居民的三线 和谐, 从而创造出适宜居住的住宅小区建筑。

\section{[参考文献]}

[1]刘博,袁野.新形势下的建筑设计与城市规划 [J].工程 技术研究,2016(08):211+217.

[2]李怡茹.住宅小区建筑规划设计的主要构思与方法 [J].住宅与房地产,2018(11):120.

[3]张科.住宅小区建筑规划设计的主要构思与设计方法 [J].建材与装饰,2018(11):122.

[4]王佳,徐州.现代居民住宅建筑设计的原则与可持续 发展 [J].建筑知识,2015(12):11. 